\title{
Multi-target Treatment for Irritable Bowel Syndrome with STW 5: Pharmacological Modes of Action
}

\author{
Hans-Dieter Allescher ${ }^{1}$, Rebecca Burgell ${ }^{2}$, Peter Malfertheiner ${ }^{3,4}$, Fermin Mearin $^{5}$
}

1) Center for Esophageal and Gastrointestinal Motility Disorders, Center for Internal Medicine, Gastroenterology, Hepatology and Metabolism, Klinikum GarmischPartenkirchen, GarmischPartenkirchen, Germany 2) Department of Gastroenterology, Central Clinical School, Monash University and Alfred Hospital, Melbourne, Victoria, Australia

3) Department of Internal Medicine II, Hospital of the Ludwig Maximilians University of Munich, Munich, Germany

4) Department of Gastroenterology, Hepatology and Infectious Diseases, Otto von Guericke University, 39106 Magdeburg, Germany 5) Servicio Aparato Digestivo, Centro Médico Teknon, Barcelona, Spain

\section{Address for correspondence: Hans-Dieter Allescher Center for Esophageal and Gastrointestinal Motility Disorders, Center for Internal Medicine, Gastroenterology, Hepatology and Metabolism, Klinikum Garmisch- Partenkirchen, Garmisch- Partenkirchen, Germany}

\section{ABSTRACT}

Irritable bowel syndrome (IBS) is a heterogeneous and complex functional gastrointestinal disorder with a global prevalence of approximately $11 \%$ and high geographic variation. IBS encompasses various symptom clusters considered to reflect complex patho-etiological mechanisms, and effective treatment options are limited, with most medications targeting individual mechanisms and symptoms. Therefore, multi-targeted treatment is required. IBS is currently viewed as a disorder of disturbed gut-brain interactions with abnormalities at different sites along the gut-brain axis, including altered gastrointestinal motility, visceral hypersensitivity, increased intestinal permeability, and altered gut microbiota. All of these abnormalities represent individual targets for STW 5, a herbal preparation with nine different extracts indicated for the treatment of functional dyspepsia and IBS. As a multi-targeted medicinal drug, STW 5 possesses multiple pharmacodynamic effects. Several in vitro and in vivo studies have demonstrated STW 5 efficacy on numerous IBS patho-mechanisms targeting gastrointestinal smooth muscles, visceral afferent nerves, inflammation, gut permeability, and the gut microbiome.

Key words: irritable bowel syndrome - hypersensitivity - visceral motility - inflammation -microbiome STW 5 - herbal medicine.

Abbreviations: CNS: central nervous system; DGBI: disturbed gut-brain interaction; EJP: excitatory junction potential; FD: functional dyspepsia; FGID: functional gastrointestinal disorder; IBS: irritable bowel syndrome.

\section{INTRODUCTION}

Functional gastrointestinal disorders (FGIDs) also termed disturbed gut-brain interactions (DGBIs) clustered alongside other disorders in functional dyspepsia (FD) and irritable bowel syndrome (IBS), often have overlapping symptoms. DGBIs are highly prevalent in the general population, with a range of $11-20 \%$ and high geographic variation $[1,2]$.

IBS is a highly heterogeneous and polymorphic syndrome, both pathophysiologically and clinically. The multifactorial origin of IBS symptoms can be explained by the biopsychosocial model, which states that early in life, genetics, sociocultural influences, and environmental factors may affect one's psychosocial development in terms of personality traits, susceptibility to life stress, psychological state, and cognitive and coping skills. These factors also influence the susceptibility to gut dysfunction (abnormal motility or sensitivity, altered mucosal immune dysfunction, or inflammation) and the microbial environment, as well as the effect of food and nutritional substances [3].

According to Rome IV, IBS is related to any combination of the following: motility disturbance, visceral hypersensitivity, altered mucosal and immune function, altered gut microbiota, and altered central nervous system (CNS) processing [3]. In most cases, FGIDs originate from different interacting pathogenic factors, though the complete underlying pathogenesis is not fully understood. IBS is the perfect example of a disorder of multifaceted origin.

Differing predominance and combinations of underlying mechanisms are likely responsible for different manifestations of IBS. Thus, IBS is characterized by recurrent abdominal pain associated with defecation or a change in bowel habits. Disordered bowel habits are typically present (i.e., constipation, diarrhea, or a mix of constipation and diarrhea), as are 
symptoms of abdominal bloating/distention [1]. The treatment of IBS is symptom based (Table I), with a preference for antispasmodics in patients with abdominal pain, anti-diarrheal medications in diarrhea type IBS (IBS-D), and laxatives in constipation type IBS (IBS-C) [4].

Table I. Treatment options for IBS depending on primary symptom

\begin{tabular}{|c|c|c|}
\hline Pain & Diarrhea & Constipation \\
\hline Antispasmodics & Loperamide & $\begin{array}{l}\text { Osmotic laxatives (i.e., } \\
\text { polyethylene glycol) }\end{array}$ \\
\hline $\begin{array}{l}\text { Antidepressants } \\
\text { (SSRIs, tricyclics) }\end{array}$ & Probiotics & $\begin{array}{l}\text { Chloride channel } \\
\text { activator (lubiproston) }\end{array}$ \\
\hline \multirow[t]{2}{*}{ Phytotherapy } & Antibiotics & $\begin{array}{l}\text { Guanylate cyclate agonist } \\
\text { (linaclotide) }\end{array}$ \\
\hline & $\begin{array}{l}\text { 5-HT3 antagonists } \\
\text { (alosetron, } \\
\text { ondansetron) }\end{array}$ & Fiber supplementation \\
\hline
\end{tabular}

SSRI: Selective serotonin reuptake inhibitor; 5HT: 5-hydroxytryptamine.

\section{PHARMACOLOGICAL MECHANISM OF STW 5}

STW 5 (Iberogast ${ }^{\oplus}$; Steigerwald, Darmstadt, Germany) is a liquid medicinal product with a fixed combination of nine hydro-ethanolic herbal extracts (Table II). It is indicated for the treatment of FD and IBS in most of the countries where it is available.

Table II. Composition of STW 5

\begin{tabular}{lcc}
\hline Medicinal plants $^{\mathrm{a}}$ & $\begin{array}{c}\text { Drug- } \\
\text { extract ratio }\end{array}$ & $\begin{array}{c}\text { Amount }(\mathrm{mL}) \text { of extract } \\
\text { in 100 mL of STW 5 }\end{array}$ \\
\hline Iberis amara L. & $1: 1.5-2.5$ & 15 \\
Carum carvi L. & $1: 2.5-3.5$ & 10 \\
Glycyrrhiza glabra L. & $1: 2.5-3.5$ & 10 \\
Mentha piperita L & $1: 2.5-3.5$ & 5 \\
Melissa officinalis L. & $1: 2.5-3.5$ & 10 \\
Matricaria chamomilla L. & $1: 2-4$ & 20 \\
Chelidonium majus L. & $1: 2.5-3.5$ & 10 \\
Silybum marianum L. Gaertn & $1: 2.5-3.5$ & 10 \\
Angelica archangelica L. & $1: 2.5-3.5$ & 10 \\
\hline
\end{tabular}

${ }^{a}$ Each herb extracted in 30:70 (by volume) ethanol:water, except Iberis amara L., which is a 50:50 (by volume) ethanol:water extract.

Numerous pharmacological mechanisms of action have been identified for STW 5 and its individual constituents [5]. The major pharmacological effects of STW 5 in the indication for IBS include region-specific action on gastrointestinal smooth muscle (spasmolytic/tonicizing), pain reduction by reducing gastrointestinal sensory afferent neuronal signaling, anti-inflammatory effects, decreasing intestinal permeability, and an influence on the microbiome, supporting that STW 5 acts as a multi-target treatment for FGIDs.

\section{Motility Effects}

Gastrointestinal tract motility is regulated by numerous factors, including 5-hydroxytryptamine $(5-\mathrm{HT})$, peristaltic reflex, or migrating motor complex. IBS is clearly associated with disturbed gastrointestinal motility and alterations in 5-HT, which regulates gastrointestinal motility and seems to play a role in its pathogenesis $[4,6,7]$.

STW 5 has pronounced effects on numerous factors influencing gastrointestinal motility in the small and large bowel. The effects of STW 5 have been shown in multiple in vitro and in vivo studies in various species and demonstrated multiple pathways of action.

The effects of STW 5 in the small intestine are regionspecific and depend on the activation state of the intestine. In different animal models, STW 5 dose-dependently decreased diverse chemically induced contractions [8], exerting mainly an inhibitory or spasmolytic effect [9]. This was confirmed in human small intestinal tissue preparations [10] by inhibiting both muscle tone and phasic activity as measured by the motility index.

In contrast, in relaxed ileum strips, STW 5 increased the basal resting tone and induced contractions in atonic ileal segments $[11,12]$. This pre-activation of the relaxed smooth muscles of the small intestine by STW 5 is associated with the modulation of the slow wave frequency in the small intestine and by inducing depolarization of the resting membrane potential of the smooth muscle $[13,14]$. This change in the slow wave activity and subsequent motility changes could also impact on the transport function of the small intestine. Furthermore, direct impact on the enteric nervous system (ENS) was shown by detecting the neural network activity; STW 5 reduced the electrical activity of the myenteric neurons, showing a direct influence of STW 5 on motor activity [9].

Similar to the results obtained in the small intestine, STW 5 had pronounced inhibitory or spasmolytic effects in the colon, inhibiting both muscle tone and motility index in vitro [10]. A similar inhibitory effect of STW 5 was found on electrically induced and neutrally mediated twitch contractions in isolated human colonic muscle strips [13].

The stimulatory effects of STW 5 in the colon were reported in different models of inflammation-induced dysmotility. STW 5 effectively prevented the inflammation-induced decrease in colonic motor response [15] and normalized the inflammation-induced attenuated small intestine and motility changes $[16,17]$.

The tonicizing effects of STW 5 due to altered electrophysiological behavior with depolarization of the smooth muscle were also detectable within the colon [14]. However, STW 5 and its components had no effect on excitatory junction potentials (EJPs). In contrast, STW 5 significantly reduced the inhibitory junction potentials (IJPs). Thus, STW 5 differentially affects the excitatory and inhibitory innervation of the smooth muscle.

In general, the relaxing effects of STW5 are regiondependent within the small and large intestine, with a decreasing gradient from the proximal duodenum to the colon, jejunum, ileum and colon. Thus, the sensitivity to electric stimuli decreases along the small bowel [11].

This two-sided effect of STW 5, stimulation of inactive muscle and inhibition of stimulated muscle, was demonstrated previously in stomach muscles, and called an "eukinetic" effect. In the stomach, STW 5 causes pronounced relaxation of fundic muscles and increased tension of antral muscles. This mode of action results from calcium channel closure (transient receptor 
potential (TRP)-channels TRPC1 and TRPC3) and a subsequent decrease in intracellular calcium in the fundus/corpus regions of the stomach. As these receptors are lacking in the antrum area, no relaxation was detectable and only the excitatory effect via the opening of L-typ calcium channels was prevalent $[10,18$ 20]. These effects were confirmed in a clinical study with healthy human volunteers in whom STW 5 elicited pronounced fundic relaxation and increased antral motor activity within 15 minutes after oral administration of the usual clinical dose of STW 5 [21].

\section{Effect on Hypersensitivity}

Abnormal visceral sensitivity is considered a key pathogenic factor in FGIDs and is seen in approximately one-third of patients depending on the method of assessment and diagnostic criteria employed [22]. The mechanisms underlying visceral hypersensitivity are complex and not completely understood. Visceral hypersensitivity is defined by increased sensitivity to different stimuli within the gut and includes both allodynia (abnormal pain response following normal stimuli) and hyperalgesia (increased sensitivity to painful stimuli) (4). An altered visceral sensory response may occur via changes in the organ itself (altered accommodation or compliance), abnormal peripheral sensory processing, or altered central processing driven by personality trait or associated psychopathology [4, $23,24]$. In patients with FGIDs, this generally manifests as enhanced awareness of gastrointestinal motility or an abnormal response to luminal distension $[25,26]$. Given the prevalence of altered visceral sensitivity in FGIDs, treatments targeting this patho-etiological mechanism are highly attractive.

Clinical studies have found that STW 5 improves sensory symptoms in patients with FD and IBS. Following 28 days of treatment, STW 5 led to complete relief of abdominal pain in $30-50 \%$ of patients with IBS, depending on location. STW 5 completely relieved the sensation of incomplete evacuation in $72 \%$ and sensation of fullness in $52 \%$ of patients [27]. In patients with FD, STW 5 significantly reduced the Gastrointestinal Symptom Score, which measures subjective symptoms, such as epigastric pain/upper abdominal pain, abdominal cramps, fullness, early satiety, loss of appetite, sickness, nausea, vomiting, retrosternal discomfort, and acid regurgitation/heartburn, to a greater degree than placebo [2831] and with similar efficacy as cisapride and metoclopramide $[32,33]$. In addition, a recent survey of complementary therapeutic use in patients with FGIDs found that the greatest symptom improvements following STW 5 use were stomach pain (in $75 \%$ of patients) and bloating (in $70 \%$ of patients), which are generally considered sensory symptoms.

STW 5 has been proposed to alter visceral sensitivity via a number of mechanisms. STW 5 causes reduced nerve sensitivity by acting directly and dose-dependently on the afferent pathway [34]. In vitro studies have shown that the phytochemical components of STW 5 interact with the serotonin receptors (5-HT-4 \& 5-HT- 3), muscarinic (M3) receptors, and opioid receptors [35]. Pre-treatment of visceral nerves with STW 5 leads to decreased mesenteric afferent nerve discharge in response to $5-\mathrm{HT}$, bradykinin, and mechanical luminal distension activating both low- and high-pressure mechanoreceptors $[34,36]$. However, direct involvement of the 5-HT-4 and 5-HT-3 receptors could not be proven.
Visceral sensitivity is also modulated by intestinal immune function with visceral afferent nerves sensitized by the release of a number of inflammatory cell mediators [23]. Patients with FGIDs have been identified as having subtle changes in mucosal inflammation and, in many cases, the onset of the disorder is attributed to an initial gastrointestinal infection (i.e., postinfectious IBS) [4]. STW 5 has anti-inflammatory properties, and it is likely that a reduction in intestinal inflammation contributes to the improvement in sensory symptoms reported in clinical studies.

\section{Effects on Inflammation}

In a subset of patients, IBS is interrelated with inflammation, as $10 \%$ of patients with gastroenteritis develop post-infectious IBS [37]. Low-grade inflammation of the gastrointestinal mucosa is detectable as increased infiltration of mucosal mast cells, as well as an increased density of mucosal T- and B-type lymphocytes in IBS patients compared to healthy controls [38, 39]. This micro-inflammation may affect changes in motility and visceral sensitivity, and evoke symptoms of IBS [40].

The effect of STW 5 on inflammation and pain has been studied in several gastrointestinal models, and potent antiinflammatory effects have been demonstrated in both in vitro and in vivo studies. In experimental rodent models of chronic inflammation, STW 5 exhibited significant mitigation of clinical markers induced by chronic inflammation, including reduced decrease in body weight, normalized histological damage, and reduced pharmacological markers, including pro-inflammatory TNF alpha, prostaglandin E3, IL-1beta, and ICAM. These effects are detectable in both the colon and small intestine $[15,16,41]$.

STW 5 seems to interact both by suppressing the protein levels of pro-inflammatory intracellular markers and by suppressing the mRNA levels [42], resulting in decreased TNF-alpha and IL-8 mRNA. In addition, translocation of transcription factor NF-kappa B and pro-inflammatory factor p65 into the nucleus is impaired by STW 5 during the resting and inflammatory state $[43,44]$.

Overall, STW 5 appears to target numerous cellular mechanisms of the inflammation cascade, leading to clinically detectable anti-inflammatory effects, which likely impact positively on symptom generation in IBS.

\section{Effects on Mucosal Barrier and Permeability}

The gastrointestinal mucosa, consisting of a single epithelial layer and the mucosal stroma, is the key barrier between the tissues and the luminal contents of the gut. A healthy gut status is maintained at the mucosal level by its tight junctions, secreted immune proteins, such as defensins, and the mucosa-associated microbiome [45-47]. Increased intestinal permeability leads to immune cell infiltration of the gut mucosa and is linked to IBS, and may be cross-linked to inflammation, as inflammatory mediators, including histamine and proteases, are able to increase intestinal permeability [48]. A percentage of $12-50 \%$ of IBS patients have altered intestinal permeability at different parts of the gastrointestinal tract [48-50].

To evaluate the influence of STW 5 on altered permeability of the gut epithelium, Aubert et al. [51] studied water-avoidance stress-induced changes in paracellular and transcellular 
permeability in specific regions of the gastrointestinal tract in in vivo and ex vivo mouse models. STW 5 prevented an increase in permeability in the distal colon ex vivo, and in the jejunum and proximal colon [51]. Such effects could contribute to the therapeutic effects of STW 5 in IBS and support novel therapeutic indications for pathologies in which barrier functions are altered.

\section{Effects on Gut Microbiota}

The communities of gut microbiota are characterized by high diversity and co-evolving together with the human organism. They are predominantly composed of bacteria (>90\%) but include virus, fungi, parasites, archaea, and protists. The gradient of microbiota density within the gastrointestinal tract apparently increases when shifting from the upper gastrointestinal tract towards the lower, being lowest in the stomach and highest in the colon. However, the microbial diversity is higher in the upper gastrointestinal tract than in the colon [52].

The microbiota develops as part of the ecological environment inside the gut and adapts to the distinct anatomical niches along the gastrointestinal tract [52]. We have to distinguish the luminal or mucosa-associated microbiome. The luminal microbiota (retrieved in feces), which is less stable and strongly influenced by diet, medications, and other exogenous factors, protects the body from pathogens [53]. The mucosa-associated microbiota (detected in biopsies) modulates the mucosal immune system, interacting directly with intestinal cells as part of the mucosal barrier.

Numerous data show evidence of an altered gut microbiome in IBS, but its role needs to be explored further [4]. The loss of eubiosis and a shift to dysbiosis in IBS is reflected by an increase in the ratio of Firmicutes to Bacteroides and abnormalities related to the relative abundance of Bifidobacteria, Clostridiales, and Faecalibacterium. Notably, Clostridiales is increased in IBS-C [54]. In a recent study, the bacterial profiles of 27 genus-like groups allowed patients with IBS to be distinguished from controls [37]. Furthermore, gut microbiota signatures and low microbial diversity have been linked to the severity of IBS symptoms [55].

An important role of microbiota in the pathogenesis of IBS is further substantiated by a series of well-documented clinical facts. Post-infectious IBS has been documented in patients followed after acute dysenteric outbreaks due to infection with Salmonella and other gut pathogens $[56,57]$. Antibiotics used in the treatment of other infections (e.g., pulmonary) are linked to the induction of IBS, likely by influencing gut microbiota eubiosis [58]. On the other hand, the antibiotic therapy proved beneficial in patients with IBS, particularly if symptoms were associated with small intestinal bacterial overgrowth [59].

Treatment options in IBS include select probiotics, mostly provided as mixtures, which benefit patients with IBS with a modest level of evidence [60]. Rifaximin, a luminally active antibiotic with no systemic effects, which is an eubiotic [61], has a significant therapeutic effect in patients with IBS-D [62]. In addition, with the recent introduction of low FODMAP, dietary interventions provide a beneficial effect on IBS symptoms via the modulation of gut microbiota [63].

Phytotherapy may impact the gut microbiota and has demonstrated promising benefits. In preparations of human fecal suspension, STW 5 induced significant changes in the composition of the microbial community, whereas the control sample remained unaffected. Bacterial taxa that were most markedly enhanced belonged to Enterococcus, Bacillus, and Paenibacillus, as well as Lactococcus strains known for exerting a probiotic effect. The strongest decrease was observed in Clostridia representatives, particularly Ruminococcaceae, as well as Bacteroidetes [64].

Two animal studies provide indications that STW 5 has an impact on the microbiome. In one of the animal studies, STW 5 reduced the dextran sulfate sodium-induced inflammation $[65,66]$, which was associated with the restoration of previously lost bacterial species Proteobacteria, Enterococcus, Blautia, and Firmicutes in the animals treated with STW 5 [67]. In a stress model applying neonatal maternal separation and restraint stress in mice, treatment of the stressed animals with STW 5 resulted in a marked increase in the beneficial microbiota, with anti-inflammatory properties, similar to Lactobacilli (2.8-fold compared to vehicle STW 5) [68].

\section{DISCUSSION}

IBS symptoms are multifactorial in origin and it is not likely that one single treatment will help every IBS patient; many patients may require a more complex approach with multidisciplinary therapy, including diet, medication, and psychotherapy, among other possibilities. At the molecular level, the patho-mechanism of IBS is multi-factorial and a single patho-mechanism is unlikely to explain the multiple symptoms of IBS. There is growing evidence that disturbances in the epithelial barrier, increased permeability, and altered gut microbiota play an important role in the etiology of IBS. Disturbances within the gut wall are linked to the immune response, and disturbed sensitivity of the visceral nerves can be associated with symptoms such as abdominal pain or disturbed motility, leading to the clinical picture of IBS [4].

Medications with a single target will help only a subset of patients suffering from specific pathophysiological abnormality. Antispasmodics, laxatives, anti-diarrheals, antinociceptives, and selective antibiotics and probiotics are used in patients with IBS and are effective in some cases. Nevertheless, they very frequently have to be used in combination to alleviate different symptoms and to achieve a more pronounced and broader effect. Consequently, multi-functional treatment of IBS will probably lead to a greater probability of a satisfactory therapeutic response.

The herbal medicinal product STW 5 has demonstrated its efficacy in FGIDs in well-designed double-blind, placebocontrolled trials [29-31, 69]. Clinical studies have shown that STW 5 has a pain-relieving effect in patients with FD and IBS. Complete pain relief occurs in 30-50\% of IBS patients after 28 days of treatment [27]. Effects on stool consistency or stool frequency were less common in a real world setting (25-30\% of patients) [70], which suggests that the clinical benefits of STW 5 are likely mediated at least in part through effects on the afferent pathways [71]. The tolerability of STW 5 has been favorable in both clinical studies and in post-marketing use [72]. Reviews of the clinical therapeutic benefit have been published recently $[73,74]$. 
This review discusses the different pharmacological effects of the nine constituent herbal extracts on numerous relevant patho-mechanisms of IBS, supporting the clinical efficacy of STW 5 in FD and IBS. The anti-inflammatory effect of STW 5 plays an important role in alleviating IBS symptoms $[16,41$, $42,44]$. The recently demonstrated effect of STW 5 on mucosal barrier permeability may contribute to this [51]. The preliminary effects of STW 5 on human microbiome composition have been limited to in vitro studies [64], but were enforced in vivo in animal studies. Furthermore, changes in the composition of the intestinal microbiota towards a normal microbiome have been shown with STW 5 [67]. The next step is to confirm the effect towards eubiosis in a study with IBS patients.

Some other properties of STW 5, such as the stimulation of mucosal ion secretion [75] and the putative beneficial effect on constipation in IBS patients [20], deserve more extensive investigation.

Regarding intestinal motor activity, STW 5 has regionspecific activities $[14,16,17]$. In general, if the muscle is in a contractile or tonic state, STW 5 decreases the activity, whereas when the muscle is in a relaxed, quiescent, or disturbed state, STW 5 increases its activity. Thus, there is a tendency to normalize the contractile activity of the intestinal smooth muscle, the so-called "eukinetic effect".

Finally, an important mechanism of action of STW 5 is its anti-nociceptive property. As visceral hypersensitivity is a key pathogenic mechanism for pain in IBS, this anti-nociceptive effect likely contributes to the clinical efficacy of STW 5, with previous in vitro and in vivo laboratory investigations demonstrating the impact of STW 5 on gut hypersensitivity $[5,76-81]$.

\section{CONCLUSIONS}

Irritable bowel syndrome is a complex disorder with multiple pathophysiological mechanisms and diverse clinical manifestations. It is hard to believe that simple solutions and monotarget treatments will be able to improve such a multifaceted syndrome. STW 5 has been shown to act through different pathophysiological pathways, treating the underlying mechanisms of IBS and prompting more general and holistic improvement of IBS symptoms.

\section{Conflicts of interest: None to declare.}

Authors' contributions: H.-D.A. concepted the storyline and wrote the chapters on motility and inflammation and finalized the manuscript. R.B. wrote the chapter on hypersensitivity. P.M. wrote the chapter on microbiota and gut barrier. F.M. concepted the discussion.

Acknowlegement: We thank San Francisco Edit (http://www. sfedit.net) for language editing, formatting and proofreading and Steigerwald Arzneimittelwerk GmbH (Bayer Consumer Health) for providing access to literature and research data on STW 5.

\section{REFERENCES}

1. Mearin F, Lacy BE, Chang L, et al. Bowel Disorders. Gastroenterology 2016;150:1393-1407. doi:10.1053/j.gastro.2016.02.031
2. Stanghellini V, Chan FK, Hasler WL, et al. Gastroduodenal Disorders. Gastroenterology 2016;150:1380-1392. doi:10.1053/j.gastro.2016.02.011

3. Drossman DA. Functional Gastrointestinal Disorders: History, Pathophysiology, Clinical Features and Rome IV. Gastroenterology 2016;150:1262-1278. doi:10.1053/j.gastro.2016.02.032

4. Enck P, Aziz Q, Barbara G, et al. Irritable bowel syndrome. Nat Rev Dis Primers 2016;2:16014. doi:10.1038/nrdp.2016.14

5. Abdel-Aziz H, Kelber O, Lorkowski G, Storr M. Evaluating the Multitarget Effects of Combinations through Multistep Clustering of Pharmacological Data: the Example of the Commercial Preparation Iberogast. Planta Med 2017;83:1130-1140. doi:10.1055/s-0043-116852

6. Cremon C, Carini G, Wang B, et al. Intestinal serotonin release, sensory neuron activation, and abdominal pain in irritable bowel syndrome. Am J Gastroenterol 2011;106:1290-1298. doi:10.1038/ajg.2011.86

7. Spiller R. Serotonin and GI clinical disorders. Neuropharmacology 2008;55:1072-80. doi:10.1016/j.neuropharm.2008.07.016

8. Abdel-Aziz H, Kelber O, Vinson B, Weiser D, Khayyal MT. Effect of a herbal preparation in a model of 5-HT3 receptor mediated ileal contraction in vitro. Gut 2007;56:A326.

9. Grundmann D, Klotz M, Burkhard W, et al. Tu1443 Influences of STW 5, a multi-component herbal preparation, on motility and inflammation challenges in gut and enteric nervous system (ENS). Gastroenterology 2016;150(Suppl 1):S905. doi:10.1016/S0016-5085(16)33066-9

10. Allam SNE. Actions of the phytopharmacon Iberogast in different regions of the gut. Dissertation Technical University of Münich. 2014.

11. Ammon HP, Kelber O, Okpanyi SN. Spasmolytic and tonic effect of Iberogast (STW 5) in intestinal smooth muscle. Phytomedicine 2006;13 Suppl 5:67-74. doi:10.1016/j.phymed.2006.08.004

12. Heinle H, Hagelauer D, Pascht U, Kelber O, Weiser D. Intestinal spasmolytic effects of STW 5 (Iberogast) and its components. Phytomedicine 2006;13 Suppl 5:75-79. doi:10.1016/j. phymed.2006.03.013

13. Sibaev A, Abdel-Aziz H, Kelber O, Allescher HD, Storr M. Mechanism of action of STW 5 and its components on motility and intestinal neurotransmission in "in vitro" model of the human colon. Neurogastroenterol Motil 2015;27(Suppl. S2):101. doi:10.1111/nmo.12598

14. Sibaev A, Yuece B, Kelber O, et al. STW 5 (Iberogast) and its individual herbal components modulate intestinal electrophysiology of mice. Phytomedicine 2006;13 Suppl 5:80-89. doi:10.1016/j. phymed.2006.03.015

15. Wadie W, Abdel-Aziz H, Zaki HF, Kelber O, Weiser D, Khayyal MT. STW 5 is effective in dextran sulfate sodium-induced colitis in rats. Int J Colorectal Dis 2012;27:1445-1453. doi:10.1007/s00384-012-1473-Z

16. Voß U, Michael S, Kelber O, Weiser D, Nieber K. Untersuchungen zur Wirkung von STW 5, STW 5-II und STW 6 auf den Tonus und die Kontraktilität an Dickdarmpräparaten der Ratte. Z Gastroenterol 2011;49:1090 P2.136.

17. Voß U, Michael S, Kelber O, Weiser D, Nieber K. Vergleichende Untersuchungen zur Wirkung von STW 5 und STW 6 auf den Tonus und die Kontraktilität an Dünn- und Dickdarmpräparaten der Ratte. Z Gastroenterol 2010;48:P265. doi:10.1055/s-0030-1263705

18. Schemann M, Michel K, Zeller F, Hohenester B, Ruhl A. Regionspecific effects of STW 5 (Iberogast) and its components in gastric fundus, corpus and antrum. Phytomedicine 2006;13 Suppl 5:90-99. doi:10.1016/j.phymed.2006.03.020

19. Hohenester B, Ruhl A, Kelber O, Schemann M. The herbal preparation STW5 (lberogast) has potent and region-specific effects on gastric motility. Neurogastroenterol Motil 2004;16:765-773. doi:10.1111/ j.1365-2982.2004.00548.x 
20. Allam S, Krueger D, Demir IE, Ceyhan G, Zeller F, Schemann M. Extracts from peppermint leaves, lemon balm leaves and in particular angelica roots mimic the pro-secretory action of the herbal preparation STW 5 in the human intestine. Phytomedicine 2015;22:1063-1670. doi:10.1016/j.phymed.2015.08.008

21. Pilichiewicz AN, Horowitz M, Russo A, et al. Effects of Iberogast on proximal gastric volume, antropyloroduodenal motility and gastric emptying in healthy men. Am J Gastroenterol 2007;102:1276-1283.

22. Simren M, Tornblom H, Palsson OS, et al. Visceral hypersensitivity is associated with GI symptom severity in functional GI disorders: consistent findings from five different patient cohorts. Gut 2018;67:255262. doi:10.1136/gutjnl-2016-312361

23. Barbara G, Cremon C, De Giorgio R, et al. Mechanisms underlying visceral hypersensitivity in irritable bowel syndrome. Curr Gastroenterol Rep 2011;13:308-315. doi:10.1007/s11894-011-0195-7

24. Farmer AD, Coen SJ, Kano M, et al. Psychophysiological responses to pain identify reproducible human clusters. Pain 2013;154:2266-2276. doi:10.1016/j.pain.2013.05.016

25. Major G, Pritchard S, Murray K, et al. Colon Hypersensitivity to Distension, Rather Than Excessive Gas Production, Produces Carbohydrate-Related Symptoms in Individuals With Irritable Bowel Syndrome. Gastroenterology 2017;152:124-133 e2. doi:10.1053/j. gastro.2016.09.062

26. Kanazawa M, Palsson OS, Thiwan SI, et al. Contributions of pain sensitivity and colonic motility to IBS symptom severity and predominant bowel habits. Am J Gastroenterol 2008;103:2550-2561. doi:10.1111/j.1572-0241.2008.02066.x.

27. Madisch A, Holtmann G, Plein K, Hotz J. Treatment of irritable bowel syndrome with herbal preparations: results of a double-blind, randomized, placebo-controlled, multi-centre trial. Aliment Pharmacol Ther 2004;19:271-279. doi:10.1111/j.1365-2036.2004.01859.x

28. von Arnim U, Peitz U, Vinson B, Gundermann KJ, Malfertheiner P. STW 5, a phytopharmacon for patients with functional dyspepsia: results of a multicenter, placebo-controlled double-blind study. Am J Gastroenterol 2007;102:1268-1275.

29. Buchert D. Efficacy and tolerability of Iberogast in patients with assured non-ulcer dyspepsia (NUD). Z Phytother 1994;15:24-25.

30. Madisch A, Holtmann G, Mayr G, Vinson B, Hotz J. Treatment of functional dyspepsia with a herbal preparation. Digestion 2004;69:4552. doi:10.1159/000076546

31. Braden B, Caspary W, Borner N, Vinson B, Schneider AR. Clinical effects of STW 5 (Iberogast(R)) are not based on acceleration of gastric emptying in patients with functional dyspepsia and gastroparesis. Neurogastroenterol Motil 2009;21:632.e25. doi:10.1111/j.13652982.2008.01249.x

32. Raedsch R, Hanisch J, Bock P, Sibaev A, Vinson B, Gundermann KJ. Assessment of the efficacy and safety of the phytopharmacon STW 5 versus metoclopramide in functional dyspepsia--a retrolective cohort study. Z Gastroenterol 2007;45:1041-1048. doi:10.1055/s-2007-963357

33. Rosch W, Vinson B, Sassin I. A randomised clinical trial comparing the efficacy of a herbal preparation STW 5 with the prokinetic drug cisapride in patients with dysmotility type of functional dyspepsia. Z Gastroenterol 2002;40:401-408. doi:10.1055/s-2002-32130

34. Muller MH, Liu CY, Glatzle J, et al. STW 5 (Iberogast) reduces afferent sensitivity in the rat small intestine. Phytomedicine. 2006;13 Suppl 5:100-106. doi:10.1016/j.phymed.2006.03.014

35. Simmen U, Kelber O, Okpanyi SN, Jaeggi R, Bueter B, Weiser D. Binding of STW 5 (Iberogast) and its components to intestinal 5-HT, muscarinic M3, and opioid receptors. Phytomedicine 2006;13 Suppl 5:51-55. doi:10.1016/j.phymed.2006.03.012

36. Liu CY, Muller MH, Glatzle J, et al. The herbal preparation STW 5 (Iberogast) desensitizes intestinal afferents in the rat small intestine. Neurogastroenterol Motil 2004;16:759-764. doi:10.1111/j.13652982.2004.00576.x

37. Jalanka-Tuovinen J, Salojarvi J, Salonen A, et al. Faecal microbiota composition and host-microbe cross-talk following gastroenteritis and in postinfectious irritable bowel syndrome. Gut 2014;63:1737-1745. doi:10.1136/gutjnl-2013-305994

38. O'Sullivan M, Clayton N, Breslin NP, , et al. Increased mast cells in the irritable bowel syndrome. Neurogastroenterol Motil 2000;12:449-457. doi:10.1046/j.1365-2982.2000.00221.x

39. Törnblom H, Lindberg G, Nyberg B, Veress B. Full-thickness biopsy of the jejunum reveals inflammation and enteric neuropathy in irritable bowel syndrome. Gastroenterology 2002;123:1972-1979. doi:10.1053/ gast.2002.37059

40. Barbara G, Cremon C, Carini G, et al. The immune system in irritable bowel syndrome. J Neurogastroenterol Motil 2011;17:349-359. doi:10.5056/jnm.2011.17.4.349

41. Abdel-Aziz H, Wadie W, Khayyal MT, Kelber O, Okpanyi S, Weiser D. Pharmacological evidence for the anti-inflammatory effect of STW 5 in colonic inflammation in vivo. Planta Med 2007;73: P_542. doi:10.1055/s-2007-987322

42. Schneider M, Efferth T, Abdel-Aziz H. Anti-inflammatory effects of herbal preparations STW5 and STW5-II in cytokine-challenged normal human colon cells. Front Pharmacol 2016;7:393. doi:10.3389/ fphar.2016.00393

43. Bonaterra GA, Kelber O, Weiser D, Kinscherf R. Mechanisms of the anti-proliferative and anti-inflammatory effects of the herbal fixed combination STW 5 (Iberogast(R)) on colon adenocarcinoma (HT29) cells in vitro. Phytomedicine 2013;20:691-698. doi:10.1016/j. phymed.2013.02.011

44. Bertalot T, Schrenk S, Facchinello N, Abdel-Aziz H. WNT signaling activation in the gut anti-inflammatory process driven by the herbal preparation STW5. United Eur Gastroenterol J 2016;2(Suppl 1):A333.

45. Öhman L, Tornblom H, Simren M. Crosstalk at the mucosal border: importance of the gut microenvironment in IBS. Nat Rev Gastroenterol Hepatol 2015;12:36-49. doi:10.1038/nrgastro.2014.200

46. Johansson ME, Sjovall H, Hansson GC. The gastrointestinal mucus system in health and disease. Nat Rev Gastroenterol Hepatol 2013;10:352-361. doi:10.1038/nrgastro.2013.35

47. Peterson LW, Artis D. Intestinal epithelial cells: regulators of barrier function and immune homeostasis. Nat Rev Immunol 2014;14:141-153. doi:10.1038/nri3608

48. Bischoff SC, Barbara G, Buurman W, et al. Intestinal permeability--a new target for disease prevention and therapy. BMC Gastroenterol 2014;14:189.doi:10.1186/s12876-014-0189-7

49. Scaldaferri F, Pizzoferrato M, Gerardi V, Lopetuso L, Gasbarrini A. The gut barrier: new acquisitions and therapeutic approaches. J Clin Gastroenterol 2012;46 Suppl:S12-S17. doi:10.1097/ MCG.0b013e31826ae849

50. Camilleri M, Madsen K, Spiller R, Greenwood-Van Meerveld B, Verne GN. Intestinal barrier function in health and gastrointestinal disease. Neurogastroenterol Motil 2012;24:503-512. doi:10.1111/j.13652982.2012.01921.x

51. Aubert P, Chevalier J, Durand T, et al. Iberogast prevents changes in intestinal permeability induced by psychological stress in mice. UEG Journal 2017;5(Suppl. 1):A559-A560. 
52. Vasapolli R, Schutte K, Schulz C, et al. Analysis of Transcriptionally Active Bacteria Throughout the Gastrointestinal Tract of Healthy Individuals. Gastroenterology 2019;157:1081-1092.e3. doi:10.1053/j. gastro.2019.05.068

53. Jacobson A, Lam L, Rajendram M, et al. A Gut Commensal-Produced Metabolite Mediates Colonization Resistance to Salmonella Infection. Cell Host Microbe 2018;24:296-307.e7. doi:10.1016/j.chom.2018.07.002

54. Rajilic-Stojanovic M, Biagi E, Heilig HG, et al. Global and deep molecular analysis of microbiota signatures in fecal samples from patients with irritable bowel syndrome. Gastroenterology 2011;141:1792-1801. doi:10.1053/j.gastro.2011.07.043

55. Tap J, Derrien M, Tornblom H, et al. Identification of an Intestinal Microbiota Signature Associated With Severity of Irritable Bowel Syndrome. Gastroenterology 2017;152:111-123.e8. doi:10.1053/j. gastro.2016.09.049

56. Marshall JK, Thabane M, Garg AX, Clark WF, Salvadori M, Collins SM. Incidence and epidemiology of irritable bowel syndrome after a large waterborne outbreak of bacterial dysentery. Gastroenterology 2006;131:445-450. doi:10.1053/j.gastro.2006.05.053

57. Marshall JK, Thabane M, Garg AX, Clark WF, Moayyedi P, Collins SM. Eight year prognosis of postinfectious irritable bowel syndrome following waterborne bacterial dysentery. Gut 2010;59:605-611. doi:10.1136/gut.2009.202234

58. Paula H, Grover M, Halder SL, et al. Non-enteric infections, antibiotic use, and risk of development of functional gastrointestinal disorders. Neurogastroenterol Motil 2015;27:1580-1586. doi:10.1111/nmo.12655

59. Ford AC, Spiegel BM, Talley NJ, Moayyedi P. Small intestinal bacterial overgrowth in irritable bowel syndrome: systematic review and metaanalysis. Clin Gastroenterol Hepatol 2009;7:1279-1286. doi:10.1016/j. cgh.2009.06.031

60. Ford AC, Harris LA, Lacy BE, Quigley EMM, Moayyedi P. Systematic review with meta-analysis: the efficacy of prebiotics, probiotics, synbiotics and antibiotics in irritable bowel syndrome. Aliment Pharmacol Ther 2018;48:1044-1060. doi:10.1111/apt.15001

61. Ponziani FR, Zocco MA, D’Aversa F, Pompili M, Gasbarrini A. Eubiotic properties of rifaximin: Disruption of the traditional concepts in gut microbiota modulation. World J Gastroenterol 2017;23:4491-4499. doi:10.3748/wjg.v23.i25.4491

62. Lembo A, Pimentel M, Rao SS, et al. Repeat Treatment With Rifaximin Is Safe and Effective in Patients With Diarrhea-Predominant Irritable Bowel Syndrome. Gastroenterology 2016;151:1113-1121. doi:10.1053/j. gastro.2016.08.003

63. Bennet SMP, Bohn L, Storsrud S, et al. Multivariate modelling of faecal bacterial profiles of patients with IBS predicts responsiveness to a diet low in FODMAPs. Gut 2018;67:872-881. doi:10.1136/ gutjnl-2016-313128

64. Moissl-Eichinger C, Koskinen K, Pferschy-Wenzig EM, Rossmann A, Abdel-Aziz H, Bauer R. Interaction between STW 5 and human intestinal bacteria in vitro. Gastroenterology 2017;152:S206. doi:10.1016/S0016-5085(17)30995-2

65. Abdel-Aziz H, Wadie W, Zaki HF, et al. Novel sequential stress model for functional dyspepsia: Efficacy of the herbal preparation STW5 Phytomedicine 2015;22:588-595. doi:10.1016/j.phymed.2015.03.012

66. Queipo-Ortuno MI, Seoane LM, Murri M, et al. Gut microbiota composition in male rat models under different nutritional status and physical activity and its association with serum leptin and ghrelin levels. PLoS One 2013;8:e65465. doi:10.1371/journal.pone.0065465
67. Khayyal MT, Wadie W, El-Sayed S, Abdel-Tawab NF, Kelber O, Abdel-Aziz H. The herbal preparation STW 5 positively influences changes in intestinal microbiota induced by functional dyspepsia or ulcerative colitis in rats. Planta Med 2017;4(S 01):S01-S202. doi:10.1055/s-0037-1608494

68. Khayyal MT, Abdeltawab M, El-Sayed S, Vinson B, Abdel-Aziz H. Effect of the herbal preparation, STW 5, on the microbiome in an experimental model of functional dyspepsia. Gastroenterology 2017;152:S1009. doi:10.1016/S0016-5085(17)33423-6

69. von Arnim U, Peitz U, Vinson B, Gundermann KJ, Malfertheiner P. STW 5, a phytopharmacon for patients with functional dyspepsia: results of a multicenter, placebo-controlled double-blind study. Am J Gastroenterol 2007;102:1268-1275.

70. Grundmann O, Yoon SL, Mason S, Smith K. Gastrointestinal symptom improvement from fiber, STW 5, peppermint oil, and probiotics useResults from an online survey. Complement Ther Med 2018;41:225-230. doi:10.1016/j.ctim.2018.10.003

71. Abdel-Aziz H, Lorkowski G, Kelber O. Complex data in herbal medicinal product research: Multi-step clustering of preclinical data for a herbal combination, STW 5. Planta Med 2017;4(S 01):S01-S202. doi:10.1055/s-0037-1608050

72. Ottillinger B, Storr M, Malfertheiner P, Allescher HD. STW 5 (Iberogast(R))--a safe and effective standard in the treatment of functional gastrointestinal disorders. Wien Med Wochenschr 2013;163:65-72. doi:10.1007/s10354-012-0169-x

73. Malfertheiner P. STW 5 (Iberogast) therapy in gastrointestinal functional disorders. Dig Dis 2017;35(Suppl. 1):25-29. doi:10.1159/000485410

74. HawrelakJA, Wohlmuth H, Pattinson M, et al. Western herbal medicines in the treatment of irritable bowel syndrome: A systematic review and meta-analysis. Complement Ther Med 2020;48:102233. doi:10.1016/j. ctim.2019.102233

75. Krueger D, Gruber L, Buhner S, et al. The multi-herbal drug STW 5 (Iberogast) has prosecretory action in the human intestine. Neurogastroenterol Motil 2009;21:1203-e110. doi:10.1111/j.13652982.2008.01242.x

76. Simmen U, Kelber O, Okpanyi SN, Jäggi R, Bueter B, Weiser D. Binding of STW 5 (Iberogast) and its components to intestinal 5-HT, muscarinic M3, and opioid receptors. Phytomedicine 2006;13:51-55. doi:10.1016/j. phymed.2006.03.012

77. Liu CY, Müller MH, Glatzle J, et al. The herbal preparation STW 5 (Iberogast) desensitizes intestinal afferents in the rat small intestine. Neurogastroenterol Motil 2004;16:759-764. doi:10.1111/j.13652982.2004.00576.x

78. Müller MH, Seeliger H, Herling N, Kasparek MS, Abdel-Aziz H, Kreis ME. Differential desensitisation of afferent nerve fibres by Iberis amara (STW 6) and Iberogast (STW 5) in the murine colon. Am J Phytomed Clin Ther 2018;6:4.

79. Mittler S, Müller MH, Kasparek MS, Kelber O, Weiser D, Kreis ME. STW 5 und seine Komponente Iberis amara verringern die Sensibilität der afferenten Mesenterialnervenfasern des Kolons der Maus in vitro. Z Gastroenterol 2011;49:P137. doi:10.1055/s-0031-1285409

80. Abdel-Aziz H, Kelber O, Vinson B, Okpanyi SN, Khayyal MT. STW 5 in a model of 5-HT3 receptor mediated ileal contraction in vitro. Z Gastroenterol 2007;45:P079. doi:10.1055/s-2007-988225

81. Khalil M, Zhang Z, Abdel-Aziz H, et al. Dual opposing actions of STW 5 on TRP receptors mediate neuronal desensitization. Manuscript under review. 2019. 